\title{
CARD15 Mutations and Perianal Fistulating Crohn's Disease: Correlation and Predictive Value of Antibiotic Response
}

\author{
Paulo Freire - Francisco Portela - Maria M. Donato • \\ Manuela Ferreira • Paulo Andrade • \\ Carlos Sofia
}

Received: 22 February 2010/ Accepted: 18 June 2010

(C) Springer Science+Business Media, LLC 2010

\begin{abstract}
Background CARD15 mutations alter bowel immunity and increase susceptibility to Crohn's disease (CD). However, the relation between these mutations and Crohn's perianal fistulas has not been fully clarified.

Aims To assess whether CARD15 mutations are associated with risk of developing Crohn's perianal fistulas and whether these mutations are predictors of the response of perianal fistulas to antibiotics.

Methods CARD15 mutations were investigated in 203 consecutive $\mathrm{CD}$ patients. Presence/absence of history of perianal fistula was recorded. Patients with history of perianal fistula were divided into two groups (with/without CARD15 mutations), and response to antibiotics was evaluated in both groups.

Results Of the 203 patients, 60 (29.6\%) showed at least one CARD15 mutation and $55(27.1 \%)$ had history of perianal fistula. History of perianal fistula was identified in $13(21.7 \%)$ patients with mutations and in $42(29.4 \%)$
\end{abstract}

\author{
P. Freire $(\bowtie) \cdot$ F. Portela $\cdot$ M. M. Donato $\cdot$ M. Ferreira . \\ P. Andrade - C. Sofia \\ Department of Gastroenterology, Coimbra University Hospital, \\ Avenida Bissaya Barreto, 3000 Coimbra, Portugal \\ e-mail: pauloavfreire@gmail.com \\ F. Portela \\ e-mail: fasportela@gmail.com \\ M. M. Donato \\ e-mail: mariamanueldonato@gmail.com \\ M. Ferreira \\ e-mail: malvesferreira@netcabo.pt \\ P. Andrade \\ e-mail: paulo_andrade@sapo.pt \\ C. Sofia \\ e-mail: carlossofia@huc.min-saude.pt
}

patients without mutations $(P=0.260)$. Mean age at diagnosis of first perianal fistula was similar in patients with/without $C A R D 15$ mutations (28.7 \pm 9.8 versus $29.7 \pm$ 10.1 years, $P=0.758$ ). Average time between disease onset and diagnosis of first perianal fistula was also similar in the two groups $(4.6 \pm 5.1$ versus $5.0 \pm 5.9$ years, $P=$ 0.816). Response of perianal fistulas to antibiotics (metronidazole alone or combined with ciprofloxacin) was significantly higher in patients without CARD15 mutations (7.7\% versus $40.5 \%, P=0.041$ ).

Conclusions In CD, CARD15 mutations are not associated with risk of developing perianal fistulas or with time of their outbreak. Nevertheless, patients with perianal fistulas and CARD15 mutations showed worse response to antibiotics.

Keywords CARD15 - Crohn's disease - Perianal fistulas . Antibiotics

\section{Introduction}

The transmural inflammation characteristic of Crohn's disease (CD) predisposes patients to formation of fistulas. Up to $43 \%$ of CD patients will develop perianal fistulas, with a significant increase of disability and direct and indirect costs, and a decrease in perceived quality of life [1-4]. The risk of developing Crohn's perianal fistulas increases when the disease involves the distal bowel. Patients with colonic $\mathrm{CD}$, particularly those with rectal involvement, have significantly higher incidence of perianal fistulas than patients without colonic involvement [2]. Indeed, only $12 \%$ of patients with isolated ileal disease develop perianal fistulas, compared with $92 \%$ of patients with rectal involvement [2]. These results were recently 
corroborated by a large cross-sectional study carried out in our country [5].

The American Gastroenterological Association technical review on perianal $C D$ recommended division of fistulas into either simple or complex [6]. A simple fistula is superficial (intersphincteric or low transsphincteric), painless, with a single external opening and no evidence of rectovaginal involvement or anorectal stricture [6]. In contrast, a complex fistula is located high (high transsphincteric, extrasphincteric or suprasphincteric), may be associated with pain, can potentially involve multiple external openings, and may be associated with rectovaginal fistula and/or anorectal stricture [6]. This is a clinically important differentiation, because several studies have shown better outcomes for patients with simple fistula tracts [7-10].

Although treatments for fistulizing perianal CD have evolved greatly over the past decade, antibiotics remain widely used and are the recommended first-line treatment for these patients, despite the absence of controlled studies to support this approach $[4,11]$. However, the response rate of perianal fistulas to antibiotics is only around $50 \%$ [12-16]. Furthermore, ineffective or inappropriate treatment of perianal fistula may lead to recurrence of the fistula or can result in the fistula progressing from simple to complex form [17]. Complex fistulas are more difficult to treat, have decreased healing rates, and are associated with less successful outcomes [7-10]. For these reasons, it would be very important to have predictors of the response of perianal fistulas to antibiotics.

The specific pathogenesis of Crohn's perianal fistulas is unknown, but luminal bacteria seem to play a role in their development and maintenance [18]. Since CARD15 mutations increase susceptibility to CD and appear to change the host response to luminal bacteria, it is reasonable to speculate on a possible connection between this gene and perianal fistulas [19-24]. However, there are few studies on the correlation between CARD15 mutations and development of Crohn's perianal fistulas, and they provided conflicting data $[25,26]$. There is also limited information on whether CARD15 variants may influence the response of perianal fistulas to treatment, namely to antibiotics [16]. In this study, we assessed whether CARD15 mutations are associated with risk of developing Crohn's perianal fistulas and whether these mutations are predictors of the response of perianal fistulas to antibiotics (metronidazole and/or ciprofloxacin).

\section{Methods}

\section{Patients}

Two hundred three consecutive patients with CD [87 males, age $($ mean \pm standard deviation $)=35.9 \pm 10.2$ years;
116 females, age (mean \pm standard deviation) $=37.1 \pm$ 7.6 years] were included in this investigation. Diagnosis of CD was based on accepted clinical, endoscopic, radiologic, and histologic criteria [27].

Ethical approval for this research was given by the local Ethics Committee. Each patient was informed of the nature of the study and signed the informed consent form, in accordance with the Declaration of Helsinki.

\section{Sample DNA Extraction}

Blood samples were collected with standard venipuncture technique using ethylenediamine tetraacetic acid (EDTA)containing tubes. Genomic DNA was isolated from whole blood using the QIAamp Mini Kit (QIAGEN GmbH, Germany).

\section{Genotyping}

All participants were genotyped for the three major CARD15 mutations: R702W (SNP8), G908R (SNP12), and 3020insC (SNP13). Genotyping was performed by realtime polymerase chain reaction (PCR): variants $\mathrm{R} 702 \mathrm{~W}$ and G908R using HybProbe (FRET), and variant 3020insC using SimpleProbe. R702W variant was amplified and detected using the forward primer $5^{\prime}$-AgCCgCACAACCT TAgATCAC- $3^{\prime}$, the reverse primer $5^{\prime}$-gCgggCACAggCAT AgC-3', the anchor probe 5'-LC Red640-gTCTggCACTC AgCCAgCAggCCCC-PH, and the donor probe $5^{\prime}-\mathrm{gCgC}$ CAgAgCAgggCCTTCTCA-FL. For assay of the G908R mutation, 5'-gCACATATCAggTACTCACTgACACT-3' was used as the forward primer, $5^{\prime}$-TTACCTgAgCCACCT CAAgC- $3^{\prime}$ as the reverse primer, 5'-LC Red705-CTgAA AAggCCAAAAgAgTCAACAgAC-PH as the anchor probe, and 5'-CCACTCTgTTgCCCCAgAA-FL as the donor probe. To detect the 3020insC variant, $\mathrm{PCR}$ was carried out using the forward primer $5^{\prime}$-gACAggTgggCTTCAgTAgA-3', the reverse primer $5^{\prime}$-TgAggTTCggAgAgCTAAAACAg-3', and the simple probe $5^{\prime}$-CTgCAggCCCCTTgAAAg-FLQ.

The reaction mixture consisted of $18 \mu \mathrm{l}$ PCR master mix plus $2 \mu \mathrm{l}$ DNA of each patient. The PCR master mix for the R702W variant included $5.0 \mathrm{mM} \mathrm{MgCl}_{2}, 1 \times$ LightCycler DNA master hybridization probes (Roche, Mannheim, Germany), $0.5 \mu \mathrm{M}$ each primer, and $0.1 \mu \mathrm{M}$ each of fluorescein and LC-Red-640-labeled probe. Cycling parameters consisted of 1 cycle of $95^{\circ} \mathrm{C}$ for $2 \mathrm{~min}$, followed by amplification for 45 cycles of $95^{\circ} \mathrm{C}$ for $0 \mathrm{~s}, 55^{\circ} \mathrm{C}$ for $10 \mathrm{~s}$, and $72^{\circ} \mathrm{C}$ for $5 \mathrm{~s}$. A melting curve was created by measuring the fluorescence signal generated with the following profile: $95^{\circ} \mathrm{C}$ for $5 \mathrm{~s}, 50^{\circ} \mathrm{C}$ for $10 \mathrm{~s}$, and $90^{\circ} \mathrm{C}$ for $0 \mathrm{~s}$ with a slope $0.4^{\circ} \mathrm{C} / \mathrm{s}$ transition. The PCR master mix for the G908R mutation included $2.5 \mathrm{mM} \mathrm{MgCl}_{2}, 1 \times$ LightCycler 
DNA master hybridization probes (Roche, Mannheim, Germany), $0.5 \mu \mathrm{M}$ each primer, and $0.2 \mu \mathrm{M}$ each of fluorescein and LC-Red-705-labeled probe. Cycling parameters consisted of 1 cycle of $95^{\circ} \mathrm{C}$ for $2 \mathrm{~min}$, followed by amplification for 40 cycles of $95^{\circ} \mathrm{C}$ for $10 \mathrm{~s}, 57^{\circ} \mathrm{C}$ for $8 \mathrm{~s}$, and $72^{\circ} \mathrm{C}$ for $17 \mathrm{~s}$. A melting curve was created by measuring the fluorescence signal generated with the following profile: $95^{\circ} \mathrm{C}$ for $20 \mathrm{~s}, 40^{\circ} \mathrm{C}$ for $20 \mathrm{~s}$, and $85^{\circ} \mathrm{C}$ for $0 \mathrm{~s}$ with a slope $0.2^{\circ} \mathrm{C} / \mathrm{s}$ transition. Finally, the PCR master mix for the 3020 insC variant included $2.5 \mathrm{mM} \mathrm{MgCl} 2,1 \times$ LightCycler DNA master hybridization probes (Roche, Mannheim, Germany), $0.2 \mu \mathrm{M}$ forward primer, $0.5 \mu \mathrm{M}$ reverse primer, and $0.2 \mu \mathrm{M}$ simple probe. Cycling parameters consisted of 1 cycle of $95^{\circ} \mathrm{C}$ for $2 \mathrm{~min}$, followed by amplification for 40 cycles of $95^{\circ} \mathrm{C}$ for $10 \mathrm{~s}, 55^{\circ} \mathrm{C}$ for $10 \mathrm{~s}$, and $72^{\circ} \mathrm{C}$ for $20 \mathrm{~s}$. A melting curve was created by measuring the fluorescence signal generated with the following profile: $95^{\circ} \mathrm{C}$ for $20 \mathrm{~s}, 40^{\circ} \mathrm{C}$ for $20 \mathrm{~s}$, and $85^{\circ} \mathrm{C}$ for $0 \mathrm{~s}$ with a slope $0.2^{\circ} \mathrm{C} / \mathrm{s}$ transition. Sterile water was used as a negative control. The change of fluorescence was converted to a melting peak (Tm) by plotting the negative derivative of the fluorescence signal corresponding to the temperature $(-\mathrm{d} F / \mathrm{d} T)$ using the LightCycler software.

The sequence variations of the PCR products were confirmed by DNA sequencing.

\section{Medical History And Outcomes}

This information was obtained from the inflammatory bowel disease database of our department and complemented by a review of patients' files. Initially we recorded whether patients developed perianal fistulas before or during follow-up. Then, in patients with history of perianal fistula, we recorded the following: gender, current age, disease location, type of fistulas (simple or complex), age at diagnosis of first perianal fistula, time between disease onset and diagnosis of first perianal fistula, antibiotics used in treatment of perianal fistulas, concomitant medication, and clinical response of perianal fistulas to antibiotic therapy.

Antibiotic therapy was defined as use of metronidazole and/or ciprofloxacin for at least 1 week. Metronidazole was used in all patients (dosage: median $980 \mathrm{mg} /$ day, range 750-1,500 mg/day) and 28 patients also received ciprofloxacin (dosage: median $970 \mathrm{mg} /$ day, range 5001,000 mg/day).

Response was defined as absence of fistula drainage, even after compression, for at least 4 weeks, according to the Fistula Drainage Assessment definition of remission and following the current recommendations for efficacy endpoints in clinical trials [28, 29].

Clinical and laboratory investigators were blinded to genetic results and to clinical data, respectively.
Definition of Groups

Patients with history of perianal fistula were divided into two groups according to presence or absence of CARD15 variants (with/without CARD15 mutations). These groups were compared for: age at diagnosis of first perianal fistula, time between disease onset and diagnosis of first perianal fistula, and clinical response of perianal fistulas to antibiotic therapy.

\section{Statistical Analysis}

Categorical variables were expressed as frequency and percentage, and corresponding contingency tables were analyzed with Pearson's chi-square test or Fisher's exact test, as appropriate. Odds ratios (OR) were determined with $95 \%$ confidence intervals $(95 \% \mathrm{CI})$.

Continuous variables were summarized using mean \pm standard deviation. These variables were tested for normal distributions using the Kolmogorov-Smirnov test. The Student's $t$ test was employed to compare means of continuous variables and normally distributed data; otherwise, the Mann-Whitney $U$ test was applied.

Only $P$ values $<0.05$ were considered significant.

All variants studied were in Hardy-Weinberg equilibrium.

Data were analyzed using the Statistical Package for Social Sciences (SPSS version 17.0; SPSS Inc., Chicago, IL, USA) software for Windows.

\section{Results}

A total of 203 patients were studied. CARD15 variants were detected in 60 patients $(29.6 \%)$, comprising 28 heterozygotes for SNP8 (13.8\%), 13 heterozygotes for SNP13 (6.4\%), 12 heterozygotes for SNP12 (5.9\%), 3 compound heterozygotes [2 (1.0\%) for SNP8/SNP12, 1 (0.5\%) for SNP12/SNP13], and 4 homozygotes [2 (1.0\%) for SNP13, $1(0.5 \%)$ for SNP8, $1(0.5 \%)$ for SNP12]. History of perianal fistula was identified in $55(27.1 \%)$ patients, including $13(21.7 \%)$ of the 60 patients with mutations and 42 (29.4\%) of the 143 patients without mutations $(P=0.865)$.

Mean age at diagnosis of first perianal fistula was similar in the two groups $(28.7 \pm 9.8$ years in patients with CARD15 mutations versus $29.7 \pm 10.1$ years in patients without $C A R D 15$ mutations, $P=0.758)$. Average time between disease onset and diagnosis of first perianal fistula was also similar in the two groups $(4.6 \pm 5.1$ years in patients with $C A R D 15$ mutations versus $5.0 \pm 5.9$ years in patients without $C A R D 15$ mutations, $P=0.816$ ).

The overall clinical response of perianal fistulas to antibiotics was $32.7 \%$ (18 of the 55 patients). This response was observed in 1 patient with CARD15 mutation and in 17 
patients without $C A R D 15$ mutations $(7.7 \%$ versus $40.5 \%$, $P=0.041$ ) (Table 1). The odds ratio, calculated for the probability of response to antibiotics in patients without mutations compared with patients with mutations, was 8.16 (95\% confidence interval 0.97-68.74). This means that the probability of response of perianal fistulas to antibiotics in CD patients without CARD15 mutations is 8.16 higher than that of patients with mutation of this gene (Table 1). The only patient with CARD15 mutation who responded to antibiotic therapy was a heterozygote for SNP8. The antibiotics used, as well as the dosage and duration of therapy, were similar in patients with and without CARD15 mutations (Table 2). Likewise we did not detect any significant differences in concomitant medication (Table 3). Finally, we found that patients with and without CARD15 mutations did not significantly differ with regard to proportion of simple/complex fistulas (1.5 in patients with CARD15 mutations versus 1.7 in patients without $C A R D 15$ mutations, $P=0.921$ ) or incidence of rectal mucosa involvement by CD $(66.6 \%$ and $55.0 \%$ in patients with and without $C A R D 15$ mutations, respectively; $P=0.519)$.

The 37 patients with perianal fistulas who did not responded to antibiotics then received the following treatments: surgery (26 patients), infliximab (8 patients), and combination surgery + infliximab (3 patients).

\section{Discussion}

Perianal fistulas are a common manifestation of CD that can lead to significant morbidity and even proctectomy [1-4].

As it is generally assumed that $\mathrm{CD}$ is a heterogeneous disease that is composed of subsets of disorders representing different pathogenic mechanisms, numerous genotypephenotype studies have been performed reporting the association of CARD15 variants with multiple characteristics of localization and behavior of CD [25, 26, 30-36]. A major problem in comparing these studies is the heterogeneity of phenotypic classifications presented, especially with regard to penetrating behavior. Some classification schemes, according to the Vienna classification, include perianal fistulas in fistulizing behavior, whereas others, following the
Montreal classification, regard anal involvement as a different entity, separate from intra-abdominal penetrating disease [25, 26, 30-38].

Few studies have specifically evaluated the correlation between CARD15 mutations and Crohn's perianal fistulas, and their results were controversial. Henckaerts et al., in a recent study involving $875 \mathrm{CD}$ patients, concluded that absence of CARD15 variants was independently associated with development of perianal fistulas [25]. In contrast, Annese et al. genotyped 360 consecutive CD patients for the three main $C A R D 15$ mutations and found, by univariate analysis, that patients who were carriers of any of the $C A R D 15$ variants presented significantly higher incidence of perianal disease [26]. Additionally, on multivariate analysis, they observed that the R720W and G908P variants were positively and negatively associated with perianal disease, respectively [26]. In our study, we did not find any association between CARD15 mutations and risk of developing Crohn's perianal fistulas, or with time of perianal fistula outbreak.

Fistula pathogenesis remains poorly understood, and therefore management of patients with Crohn's perianal fistulas remains challenging. Nevertheless, there is evidence suggesting that luminal bacteria might play a role in development and maintenance of fistulas [18, 39-41]. Perhaps for this reason, antibiotics are a widely used and recommended first-line treatment for fistulas in $C D$ patients, despite the near absence of randomized controlled trials supporting this approach [4, 11]. As only $50 \%$ of patients respond to this therapy, predictors for selection of patients for antibiotic treatment are crucial [12-16]. This is even more relevant if we remember that inadequate treatment of perianal fistula may lead to fistula recurrence or can result in the fistula progressing from simple to complex form [17].

Regarding the response of perianal fistulas to antibiotics, our results show that this is positively associated with absence of CARD15 mutations (Table 1). It may be thought that the best response to antibiotics observed in these patients could be related to factors other than CARD15 genotype [2, 42-44]. This was ruled out by demonstrating no significant differences between patients with and without $C A R D 15$ variants in relation to other factors with a

Table 1 CARD15 mutations versus response of perianal fistulas to antibiotics

\begin{tabular}{|c|c|c|c|c|c|}
\hline & \multirow[t]{2}{*}{ Total, $n$} & \multicolumn{2}{|c|}{ Response of perianal fistulas to antibiotics } & \multirow[t]{2}{*}{$P$} & \multirow[t]{2}{*}{ OR $(95 \% \mathrm{CI})^{*}$} \\
\hline & & Yes, $n(\%)$ & No, $n$ & & \\
\hline Patients with $C A R D 15$ mutations & 13 & $1(7.7)$ & 12 & 0.041 & $8.16(0.97-68.74)$ \\
\hline Patients without $C A R D 15$ mutations & 42 & $17(40.5)$ & 25 & & \\
\hline
\end{tabular}

$O R$ odds ratio, $C I$ confidence interval

* Calculated for the probability of response to antibiotics in patients without mutations compared with patients with mutations 
Table 2 Characteristics of antibiotic therapy: patients with CARD15 mutations versus patients without $C A R D 15$ mutations

\begin{tabular}{llll}
\hline & $\begin{array}{l}\text { With CARD15 } \\
\text { mutations }\end{array}$ & $\begin{array}{l}\text { Without CARD15 } \\
\text { mutations }\end{array}$ & $P$ \\
\hline Ciprofloxacin alone (\% of patients) & 0 & 0 & - \\
Metronidazole alone (\% of patients) & 44.4 & 50 & 0.803 \\
Ciprofloxacin and metronidazole (\% of patients) & 55.6 & 50 & 0.783 \\
Ciprofloxacin: dosage (mg/day) & $1,000 \pm 0$ & $961 \pm 138.7$ & 0.551 \\
Metronidazole: dosage (mg/day) & $1,138 \pm 356$ & $932 \pm 371$ & 0.160 \\
Ciprofloxacin: duration (weeks) & $6.0 \pm 2.4$ & $6.1 \pm 3.3$ & 0.963 \\
Metronidazole: duration (weeks) & $8.0 \pm 7.0$ & $9.2 \pm 8.0$ & 0.687 \\
\hline
\end{tabular}

\begin{tabular}{lccc}
\hline & $\begin{array}{l}\text { With CARD15 } \\
\text { mutations (\%) }\end{array}$ & $\begin{array}{l}\text { Without CARD15 } \\
\text { mutations (\%) }\end{array}$ & $P$ \\
\hline Without medication & 25.0 & 39.5 & 0.431 \\
5-ASA & 75.0 & 58.1 & 0.375 \\
Steroids & 25.0 & 7.0 & 0.148 \\
Azathioprine, $<3$ months & 9.0 & 19.0 & 0.251 \\
Azathioprine, $\geq 3$ months & 25.0 & 9.0 & 0.162 \\
\hline
\end{tabular}

Table 3 Concomitant medication: patients with CARD15 mutations versus patients without $C A R D 15$ mutations

\section{5-ASA 5-aminosalicylic acid}

potential effect on the response. In fact, we found no significant differences between these two groups of patients with regard to the characteristics of antibiotic therapy (Table 2), concomitant medication (Table 3), proportion of simple/complex fistulas or incidence of rectal mucosa involvement by $\mathrm{CD}$.

Angelberger et al., in a prospective study including $52 \mathrm{CD}$ patients with perianal fistulas treated with antibiotics, also found better clinical response in patients without CARD15 mutations [16]. Nevertheless, in that work ciprofloxacin was used as first-line treatment, while in our study all patients received metronidazole, with or without ciprofloxacin (association with ciprofloxacin in about half of the cases). Thus, to our knowledge, our study is the first to show that CARD15 genotype predicts the response of Crohn's perianal fistulas to treatment with metronidazole alone or in combination with ciprofloxacin. Based on our results, we suggest that antibiotics should be questioned as first-line treatment in perianal fistulas of $C D$ patients with $C A R D 15$ variants.

Usually infliximab is recommended as second-line treatment for Crohn's perianal fistulas when first-line treatment (antibiotics and/or azathioprine/6-mercaptopurine) fails $[4,11]$. Nevertheless, given the low response rate of Crohn's perianal fistulas to antibiotics and/or azathioprine/6-mercaptopurine and the encouraging results of infliximab in this setting, some authors consider a "topdown" approach as an option for these patients [4, 11-16]. Our results, demonstrating that CARD15 genotype seems to predict clinical response of perianal fistulas to antibiotics, suggest that $C A R D 15$ genotype may be a factor in selection of patients with perianal fistulas for a "top-down" approach. This interesting hypothesis needs to be tested in randomized controlled studies.

There is, so far, no explanation for our observation of a greater response to antibiotics in Crohn's perianal fistulas of CARD15 wild-type patients. However, we know that CARD15 plays a role in bowel immunity by participating in recognition of intestinal bacteria [21-24]. Thus, we can speculate that, in CARD15 wild-type patients, endogenous antimicrobial activity may synergize with antibiotics to enhance their action, while in patients with CARD15 mutations this synergy does not occur. This speculation is reinforced by some recent data that support an association between CARD15 mutations and increased risk of several infectious complications [45-47].

Some limitations of our study should be mentioned. Firstly, characterization and evaluation of fistulas were carried out retrospectively. Secondly, the size of the study population is relatively small. Finally, this work was performed in an academic referral hospital; therefore, our results may not be applicable to institutions with different patient populations.

Our work shows how gene identification strategies combined with genotype-phenotype correlations might identify prognostic markers to guide disease management. In the future, randomized controlled studies are highly warranted to confirm our results and to identify more prognostic markers in order to define the optimum approach for treatment of this challenging, and often serious, complication of $\mathrm{CD}$. 
In conclusion, our study suggests that CARD15 mutations are not associated with risk of developing Crohn's perianal fistulas, or with time of perianal fistula manifestation. Nevertheless, in our series, CARD15 genotype seems to predict clinical response of perianal fistulas to antibiotic treatment. In fact, CD patients with perianal fistulas and CARD15 mutations showed worse response to antibiotic therapy with metronidazole alone or in combination with ciprofloxacin. Thus, in the light of our findings, we propose that antibiotics should be questioned as firstline treatment for Crohn's perianal fistulas in patients with CARD15 mutations. Such patient selection might avoid delay in application of effective treatment and minimize the risk of adverse events under antibiotic treatment.

Conflicts of interest statement We declare that we have no conflicts of interest.

\section{References}

1. Schwartz DA, Herdman CR. Review article: the medical treatment of Crohn's perianal fistulas. Aliment Pharmacol Ther. 2004;19:953-967.

2. Hellers G, Bergstrand O, Ewerth S, Holmström B. Occurrence and outcome after primary treatment of anal fistulae in Crohn's disease. Gut. 1980;21:525-527.

3. Schwartz DA, Loftus EV Jr, Tremaine WJ, et al. The natural history of fistulizing Crohn's disease in Olmsted County, Minnesota. Gastroenterology. 2002;122:875-880.

4. Nielsen OH, Rogler G, Hahnloser D, Thomsen OØ. Diagnosis and management of fistulizing Crohn's disease. Nat Clin Pract Gastroenterol Hepatol. 2009;6:92-106.

5. Magro F, Portela F, Lago P, et al. Crohn's disease in a southern European country: montreal classification and clinical activity. Inflamm Bowel Dis. 2009;15:1343-1350.

6. American Gastroenterological Association Clinical Practice Committee. American Gastroenterological Association medical position statement: perianal Crohn's disease. Gastroenterology. 2003;125:1503-1507.

7. Bell SJ, Williams AB, Wiesel P, Wilkinson K, Cohen RC, Kamm MA. The clinical course of fistulating Crohn's disease. Aliment Pharmacol Ther. 2003;17:1145-1151.

8. Regueiro M, Mardini H. Treatment of perianal fistulizing Crohn's disease with infliximab alone or as an adjunct to exam under anesthesia with seton placement. Inflamm Bowel Dis. 2003;9: 98-103.

9. Scott HJ, Northover JM. Evaluation of surgery for perianal Crohn's fistulas. Dis Colon Rectum. 1996;39:1039-1043.

10. Topstad DR, Panaccione R, Heine JA, Johnson DR, MacLean AR, Buie WD. Combined seton placement, infliximab infusion, and maintenance immunosuppressives improve healing rate in fistulizing anorectal Crohn's disease: a single center experience. Dis Colon Rectum. 2003;46:577-583.

11. Caprilli R, Gassull MA, Escher JC, et al. European evidence based consensus on the diagnosis and management of Crohn's disease: special situations. Gut. 2006;55:i36-i58.

12. Dejaco C, Harrer M, Waldhoer T, Miehsler W, Vogelsang H, Reinisch W. Antibiotics and azathioprine for the treatment of perianal fistulas in Crohn's disease. Aliment Pharmacol Ther. 2003; 18:1113-1120.
13. Brandt LJ, Bernstein LH, Boley SJ, Frank MS. Metronidazole therapy for perineal Crohn's disease: a follow-up study. Gastroenterology. 1982;83:383-387.

14. Jakobovits J, Schuster MM. Metronidazole therapy for Crohn's disease and associated fistulae. Am J Gastroenterol. 1984;79: 533-540.

15. Turumen U, Fakkila M, Yaltonen V. Longterm outcome of ciprofloxacin treatment in severe perianal or fistulous Crohn's disease. Gastroenterology. 1993;104:A793.

16. Angelberger S, Reinisch W, Dejaco $\mathrm{C}$, et al. NOD2/CARD15 gene variants are linked to failure of antibiotic treatment in perianal fistulating Crohn's disease. Am J Gastroenterol. 2008;103:1197-1202.

17. Williamson PR, Hellinger MD, Larach SW, Ferrara A. Twentyyear review of the surgical management of perianal Crohn's disease. Dis Colon Rectum. 1995;38:389-392.

18. West RL, Van der Woude CJ, Endtz HP, et al. Perianal fistulas in Crohn's disease are predominantly colonized by skin flora: implications for antibiotic treatment? Dig Dis Sci. 2005;50: $1260-1263$.

19. Hugot JP, Chamaillard M, Zouali $\mathrm{H}$, et al. Association of NOD2 leucine-rich repeat variants with susceptibility to Crohn's disease. Nature. 2001;411:599-603.

20. Ogura Y, Bonen DK, Inohara N, et al. A frameshift mutation in NOD2 associated with susceptibility to Crohn's disease. Nature. 2001;411:603-606.

21. Inohara N, Ogura Y, Fontalba A, et al. Host recognition of bacterial muramyl dipeptide mediated through NOD2. Implications for Crohn's disease. J Biol Chem. 2003;278:5509-5512.

22. Kobayashi KS, Chamaillard M, Ogura Y, et al. NOD2-dependent regulation of innate and adaptive immunity in the intestinal tract. Science. 2005;307:731-734.

23. Wehkamp J, Harder J, Weichenthal M, et al. NOD2 (CARD15) mutations in Crohn's disease are associated with diminished mucosal alpha-defensin expression. Gut. 2004;53:1658-1664.

24. Bonen DK, Ogura Y, Nicolae DL, et al. Crohn's disease-associated $N O D 2$ variants share a signaling defect in response to lipopolysaccharide and peptidoglycan. Gastroenterology. 2003;124:140-146.

25. Henckaerts L, Van Steen K, Verstreken I, et al. Genetic risk profiling and prediction of disease course in Crohn's disease patients. Clin Gastroenterol Hepatol. 2009;7:972-980. e2.

26. Annese V, Lombardi G, Perri F, et al. Variants of CARD15 are associated with an aggressive clinical course of Crohn's disease-an IG-IBD study. Am J Gastroenterol. 2005;100:84-92.

27. Stange EF, Travis SP, Vermeire S, et al. European Crohn's and Colitis Organisation. European evidence based consensus on the diagnosis and management of Crohn's disease: definitions and diagnosis. Gut. 2006;55:11-i15.

28. Present DH, Rutgeerts $\mathrm{P}$, Targan $\mathrm{S}$, et al. Infliximab for the treatment of fistulas in patients with Crohn's disease. $N$ Engl J Med. 1999;340:1398-1405.

29. Sandborn WJ, Feagan BG, Hanauer SB, et al. A review of activity indices and efficacy endpoints for clinical trials of medical therapy in adults with Crohn's disease. Gastroenterology. 2002;122:512-530.

30. Vermeire S, Wild G, Kocher K, et al. CARD15 genetic variation in a Quebec population: prevalence, genotype-phenotype relationship, and haplotype structure. Am J Hum Genet. 2002;71: 74-83.

31. Lesage S, Zouali H, Cézard JP, et al. CARD15/NOD2 mutational analysis and genotype-phenotype correlation in 612 patients with inflammatory bowel disease. Am J Hum Genet. 2002;70:845-857.

32. Abreu MT, Taylor KD, Lin YC, et al. Mutations in NOD2 are associated with fibrostenosing disease in patients with Crohn's disease. Gastroenterology. 2002;123:679-688. 
33. Heliö T, Halme L, Lappalainen M, et al. CARD15/NOD2 gene variants are associated with familially occurring and complicated forms of Crohn's disease. Gut. 2003;52:558-562.

34. Economou M, Trikalinos TA, Loizou KT, Tsianos EV, Ioannidis JP. Differential effects of NOD2 variants on Crohn's disease risk and phenotype in diverse populations: a metaanalysis. Am J Gastroenterol. 2004;99:2393-2404.

35. Lakatos PL, Lakatos L, Szalay F, et al. Toll-like receptor 4 and NOD2/CARD15 mutations in Hungarian patients with Crohn's disease: phenotype-genotype correlations. World J Gastroenterol. 2005;11:1489-1495.

36. Radford-Smith G, Pandeya N. Associations between NOD2/ CARD15 genotype and phenotype in Crohn's disease-Are we there yet? World J Gastroenterol. 2006;12:7097-7103.

37. Gasche C, Scholmerich J, Brynskov J, et al. A simple classification of Crohn's disease: report of the Working Party for the World Congresses of Gastroenterology, Vienna 1998. Inflamm Bowel Dis. 2000;6:8-15.

38. Silverberg MS, Satsangi J, Ahmad T, et al. Toward an integrated clinical, molecular and serological classification of inflammatory bowel disease: Report of a Working Party of the 2005 Montreal World Congress of Gastroenterology. Can J Gastroenterol. 2005;19:5-36.

39. Janowitz HD, Croen EC, Sachar DB. Role of the faecal stream in the maintenance of Crohn's colitis. Gut. 1985;26: 279-284.
40. Yamamoto T, Allan RN, Keighley MR. Effect of fecal diversion alone on perianal Crohn's disease. World J Surg. 2000;24: $1258-1262$.

41. Gaertner WB, Decanini A, Mellgren A, et al. Does infliximab infusion impact results of operative treatment for Crohn's perianal fistulas? Dis Colon Rectum. 2007;50:1754-1760.

42. Nordgren S, Fasth S, Hultén L. Anal fistulas in Crohn's disease: incidence and outcome of surgical treatment. Int J Colorectal Dis. 1992;7:214-218.

43. Sandborn WJ, Fazio VW, Feagan BG, Hanauer SB. American Gastroenterological Association Clinical Practice Committee. AGA technical review on perianal Crohn's disease. Gastroenterology. 2003;125:1508-1530.

44. Halme L, Sainio AP. Factors related to frequency, type, and outcome of anal fistulas in Crohn's disease. Dis Colon Rectum. 1995;38:55-59.

45. Ahrens P, Kattner E, Köhler B, et al. Mutations of genes involved in the innate immune system as predictors of sepsis in very low birth weight infants. Pediatr Res. 2004;55:652-656.

46. Brenmoehl J, Herfarth H, Glück T, et al. Genetic variants in the NOD2/CARD15 gene are associated with early mortality in sepsis patients. Intensive Care Med. 2007;33:1541-1548.

47. den Hartog JE, Ouburg S, Land JA, et al. Do host genetic traits in the bacterial sensing system play a role in the development of Chlamydia trachomatis-associated tubal pathology in subfertile women? BMC Infect Dis. 2006;6:122. 